\title{
ESCOLA, CURRÍCULO E COMPETÊNCIAS SOCIOEMOCIONAIS: UMA NOVA GOVERNAMENTALIDADE?
}

\author{
ADEMIR HENRIQUE MANFRÉ1. \\ ${ }^{1}$ Doutor em Educação. Docente da Faculdade de Artes, Ciências, Letras e Educação (FACLEPP) da \\ UNOESTE. ademirmanfre@yahoo.com.br.
}

\section{RESUMO}

Este artigo analisa o conceito de competências socioemocionais oriundo das políticas curriculares educacionais brasileiras. Sabe-se que o conceito de competências já foi há muito utilizado no decorrer da história do currículo escolar. Entretanto, na atualidade, o conceito surge numa perspectiva socioemocional demandando a formação de um conjunto de habilidades e procedimentos necessários para o indivíduo sobreviver no contexto do chamado empreendedorismo, do empresário de si. $\mathrm{O}$ texto assume o desafio de analisar as transformações do projeto educacional neoliberal contemporâneo. Essa proposta se deu a partir do conceito foucaultiano de governamentalidade. O objetivo desse debate é contribuir para uma reflexão crítica oferecendo meios para compreender os limites de uma concepção pedagógica de competências sujeitada aos imperativos neoliberais.

Palavras-chave: Competências socioemocionais; Empresário de si; Governamentalidade.

\section{SCHOOL, CURRICULUM, AND SOCIOEMOTIONAL COMPETENCES: A NEW GOVERNMENTALITY?}

\begin{abstract}
This paper analyzes the concept of socioemotional competences from Brazilian educational curricular politics. It is known that the concept of competence has already been used during the history of school curriculum. However, nowadays, such concept arises from socioemotional perspective requiring the constitution of a set of skills and procedures needed to the surviving of the individual in the context of the so-called entrepreneurship, of the self-entrepreneur. In this paper we assume de challenge of analyzing the transformation of the contemporary neoliberal project for education. This proposal was developed from the Foucault's concept of governmentality. The aim of this debate is to contribute for a critical thinking that could provide alternativities to understand the limits of a pedagogical conception of competence subjected by neoliberal imperatives.
\end{abstract}


Keywords: Socioemotional Competences; Governmentality. Self-entrepreneur.

\section{INTRODUÇÃO}

Este artigo analisa o conceito de competências socioemocionais oriundo das políticas curriculares educacionais atuais. É resultado de elaborações teóricas desenvolvidas junto à disciplina de Currículo e Escola pelo autor ministrada num curso superior de formação de professores. Sabe-se que o conceito de competências já foi há muito utilizado no decorrer da história do Currículo Escolar. Entretanto, na atualidade, o referido conceito surge numa perspectiva socioemocional demandando a formação de um conjunto de habilidades e procedimentos necessários para o indivíduo sobreviver no contexto do chamado empreendedorismo (self made man), do empresário de si. O texto assume o desafio de analisar as transformações e contradições do projeto educacional neoliberal contemporâneo.

Para começar esse debate, destacamos o texto "Disciplina e controle na escola: do aluno dócil ao aluno flexível" em que Moraes (2008) destacou uma transformação que vem ocorrendo na dinâmica das relações sociais contemporâneas, dinâmica esta marcada pela flexibilização da formação que afeta a subjetividade dos sujeitos.

\footnotetext{
Os alunos e professores, nesse contexto, têm de desenvolver competências e habilidades de modo a serem pessoalmente flexíveis e aptos a agirem em contextos que não têm nenhum conjunto claro de fronteiras ou respostas simples. Professor e aluno devem desenvolver competências para a contínua resolução de problemas de forma flexível, num processo contínuo de adaptação a situações complexas (MORAES, 2008, p. 57).
}

Veiga-Neto (2011) ressaltou as afirmações de Moraes (2008) ao enfatizar que a educação contemporânea tem passado pela definição de novas competências e habilidades determinadas pela Base Nacional Comum Curricular (BNCC) como referências obrigatórias para a elaboração dos currículos escolares.

Assim, nota-se que os processos de ensino e de aprendizagem escolares atuais têm uma relação alinhada à lógica empresarial, abrindo espaços para empreendimentos da formação profissional dos indivíduos assujeitados aos imperativos neoliberais. 
Diante da amplitude que caracteriza a temática, é necessário refletir: que tipo de razão governamental está presente na chamada pedagogia das competências socioemocionais?

$\mathrm{Na}$ sociedade caracterizada como neoliberal, prioriza-se a formação de um capital humano permeado por competências e habilidades assumindo a educação um elemento estratégico de legitimação dos imperativos do mundo do trabalho.

Diante dessa perspectiva, nota-se a transferência de características do sujeitoempresa como modelo para a formação dos estudantes nos quais os seguintes perfis são requeridos: "pró-ativos, inovadores, inventivos, flexíveis, etc" (GADELHA, 2009, p. 156).

É nesse contexto que se insere o debate sobre competências socioemocionais.

\section{INICIANDO O DEBATE SOBRE COMPETÊNCIAS SOCIOEMOCIONAIS NA EDUCAÇÃO}

Figura 1- Self-Mad Man
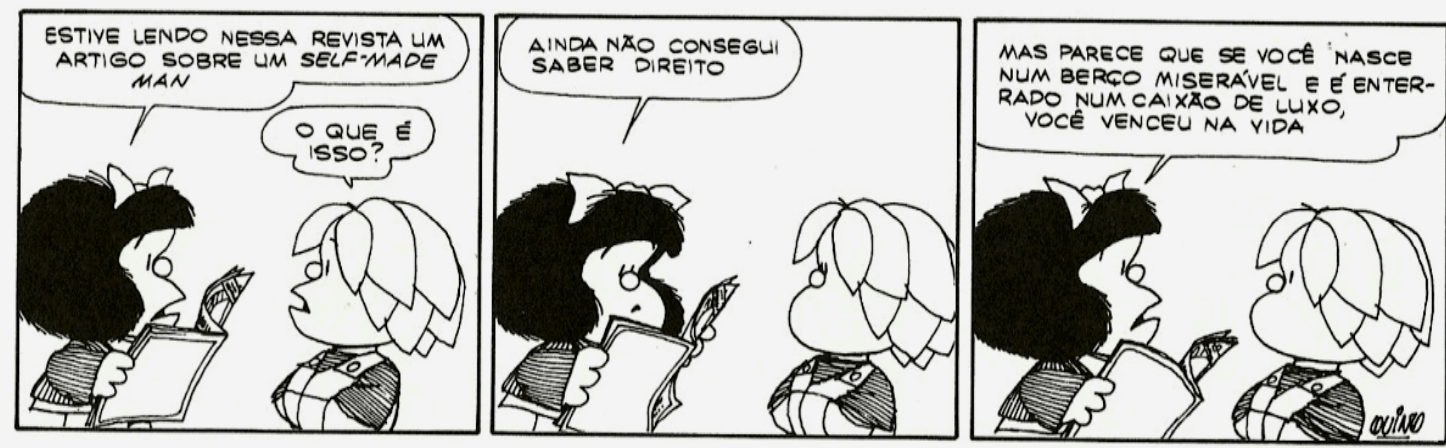

Fonte: http://sociedadesemprisoes.blogspot.com/2011/12/mafalda-self-made-man.html

Mafalda - personagem do cartunista Quino - reproduz o discurso presente nos últimos tempos sobre a inclusão no currículo escolar de competências e habilidades tão requeridas para o almejado sucesso profissional e pessoal dos indivíduos. Habilidades cognitivas, competências racionais, aprendizagem racional, competências para o século XXI, competências socioemocionais são os diferentes termos utilizados para nomear os aspectos almejados na formação dos nossos estudantes na contemporaneidade. Essa polissemia conceitual evidencia que a escola enfrenta muitos desafios, uma vez que ela 
pode não estar respondendo às demandas da contemporaneidade, permitindo que se discuta a formação de um "novo" indivíduo: competitivo, com capacidade de aprender a aprender constantemente, e mais, com capacidade de aprender a empreender.

De acordo com Carvalho e Silva (2017, p. 175), “evidencia-se, em nosso tempo, uma difusão de modelos de currículos que tomam a infância como alvo privilegiado para o investimento econômico". Assim, levando-se em consideração o contexto em que são retratadas, as competências são definidas de diferentes formas.

Segundo Perrenoud (1999, p. 19), "não existe uma definição clara e compartilhada". Porém, as definições mais comuns são as de utilização eficiente de recursos e experiências práticas contextualizadas.

De acordo com a Organização para a Cooperação e Desenvolvimento Econômico (OCDE), uma competência é a capacidade de mobilizar conhecimentos práticos para resolver determinados problemas cotidianos. Desse ponto de vista, cada competência se desenvolve a partir de um conjunto de habilidades cognitivas e práticas, incluindo as emoções e outros elementos sociais.

Diante do exposto, as definições apontadas acima elegem como palavras-chave para as competências a capacidade, a eficácia e a eficiência aplicadas em um determinado contexto, associando a escola a uma organização empresarial.

Em nosso entendimento, não há problema algum em relacionar as competências à Educação, uma vez que a articulação histórica da educação ao trabalho já foi expressa na Lei de Diretrizes e bases da Educação Nacional (Lei n 9394/96). O problema é quando os princípios básicos para uma formação integral são deslocados para a aquisição de necessidades técnicas que o mercado global impõe aos processos formativos escolares.

Estabelecidas na área da Administração, bem antes de sua inserção na Educação, as competências são definidas como capacidades técnicas e teóricas aplicadas de forma eficiente às situações-problema presentes na prática profissional (GADELHA, 2009).

No contexto educacional, o enfoque por competências visa o desenvolvimento de um comportamento empreendedor, do empresário de si, atuando nas áreas cognitiva, afetiva, profissional e produtiva, afirmou Gadelha (2009).

Também notamos no discurso contemporâneo a proliferação dos chamados "treinadores/instrutores" - denominados de coach - ou seja, aqueles que se prontificam 
a instruir seu aprendiz a adquirir capacidades essenciais para o exercício profissional através de treinamentos. Essa oferta de coach aponta para uma lógica competitiva do ganhar ou perder, assim como do superar-se continuamente, elementos ressaltados na charge de Quino.

Não é por acaso que a proposta de competências socioemocionais surge dos trabalhos de James Heckman, um famoso economista norte-americano ganhador do prêmio nobel de economia em 2000, sendo rapidamente disseminada por Instituições e movimentos que representam interesses privados na Educação. Segundo esse teórico, “[...] dar dinheiro às famílias pobres não promove, por si só, a mobilidade social pelas gerações seguintes. Os recursos escassos são o amor e o cuidado parental - não dinheiro" (HECKMAN, 2013, [s/p]).

A discussão sobre a formação de competências socioemocionais nas políticas curriculares educacionais brasileiras teve início no ano de 2011 quando, por iniciativa do Instituto Ayrton Senna (IAS), houve a realização do "Seminário Educação para o século 21". Tendo a parceria da Organização das Nações Unidas para a Educação, a Ciência e a Cultura (UNESCO), da Secretaria de Assuntos Estratégicos (SAE) da Presidência da República, o IAS apresentou alguns estudos realizados por Heckman.

Tais estudos destacavam a importância das competências socioemocionais como elementos promotores do desempenho escolar de crianças e de adolescentes.

Além desse evento, seguiram-se outros, como o ocorrido em 2014, em São Paulo: "Fórum Internacional de Políticas Públicas: educar para a competências do século 21". Organizado pelo Ministério da Educação (MEC), pelo IAS e pela OCDE, participaram representantes de 14 países membros da OCDE.

No referido evento, os países participantes reconheceram a importância das competências socioemocionais na preparação dos indivíduos para o mundo do trabalho.

Reunidos em sessões fechadas, os 14 países participantes ousaram em apresentar propostas e estratégias mediadas pelas competências socioemocionais no sentido de promover políticas públicas educacionais eficientes nas escolas brasileiras. O discurso propagado foi o de que a escola pública vive uma crise aguda. Logo, é necessária uma ampla reforma curricular ${ }^{1}$.

\footnotetext{
${ }^{1}$ Exemplos de reformas neoliberais: Lei ${ }^{\circ} 13.415 / 17$ que reformou o Ensino Médio Brasileiro, a Lei $n^{\circ}$ 13.005/14, que instituiu o Plano Nacional de Educação, entre outras.
} 
Diante da amplitude que caracteriza a temática, nota-se que as organizações privadas e multilaterais tomaram as rédeas das políticas educacionais e impuseram modelos formativos assujeitando nossas crianças e adolescentes aos imperativos neoliberais.

Assim, no contexto brasileiro, há uma defesa das competências socioemocionais, principalmente aquelas provenientes do Instituto Ayrton Senna.

Em "O desenvolvimento das habilidades socioemocionais como caminho para a aprendizagem e o sucesso escolar de alunos da educação básica", documento encomendado pelo Ministério da Educação (MEC) à UNESCO (2014), temos a definição de competências socioemocionais:

\begin{abstract}
Capacidades individuais que podem ser manifestadas com um padrão consistente de pensamentos, sentimentos e comportamentos, desenvolvidas por meio de experiências de aprendizagem formais e informais; e importantes impulsionadoras de resultados socioemocionais ao longo da vida do indivíduo (UNESCO, 2014, p. 26).
\end{abstract}

O referido documento ainda apresenta um pequeno roteiro para a reorganização curricular $^{2}$ dos sistemas de ensino baseado nas competências socioemocionais.

Também em 2014, a OCDE, em parceria com o Instituto Ayrton Senna e com a Secretaria Estadual de Educação do Rio de Janeiro, projetou à comunidade educacional uma proposta de mensuração das chamadas competências socioemocionais conhecida como SENNA ${ }^{3}$. Trata-se de um questionário com perguntas variadas sobre comportamentos e características de personalidades que um indivíduo dever ter.

Em um estudo com a participação de mais de 25 mil estudantes do Rio de Janeiro, mostrou-se que os indivíduos com competências socioemocionais mais atuantes tendem a ter melhor desempenho acadêmico, insinuando ainda que essas competências podem ser estimuladas por meio da intervenção de políticas públicas eficientes (IAS, 2015).

\footnotetext{
${ }^{2}$ Segundo a UNESCO (2014), os currículos escolares devem promover a formação de um indivíduo flexível que seja capaz de estar aberto ao contexto emocional; seja capaz de perceber, ponderar, atribuir sentido a várias emoções; seja capaz de conciliar emoção e razão; seja capaz de regrar emoções; seja capaz de acolher, acalmar.

${ }^{3}$ Do inglês "Social and Emotional or Non-cognitive Nationwide Assessment", esse modelo, em forma de questionário, tem como princípio básico analisar a personalidade humana a partir de 5 dimensões: abertura a novas experiências; extroversão, amabilidade; conscienciosidade e estabilidade emocional. Inicialmente, foi aplicado como Projeto Piloto nas escolas de $5^{\circ}$ ano do Ensino Fundamental ao $3^{\circ}$ ano do Ensino Médio do Rio de Janeiro.
} 
Quando aplicados a pessoas de diferentes culturas e em diferentes momentos do tempo, esses questionários demonstraram ter a mesma estrutura fatorial latente, dando origem à hipótese de que os traços da personalidade dos seres humanos se agrupariam efetivamente em torno de grandes domínios afetivos e cognitivos (PRIMI; SANTOS, 2014, p. 16).

Segundo os representantes da OCDE e do IAS, as políticas públicas curriculares, por muito tempo, negligenciaram a perspectiva socioemocional ${ }^{4}$ na escola, defendida como um elemento essencial para os estudantes atingirem o sucesso pessoal e profissional. O documento ressalta ainda o baixo desempenho do Brasil no Programa Internacional de Avaliação de Alunos (PISA) justificando, com isso, a importância do desenvolvimento de competências socioemocionais como forma de alavancar o desempenho dos estudantes nos processos avaliativos.

Diante do assinalado e pautando-se numa leitura simplista, não há como ser contrário à abordagem otimista das competências socioemocionais na educação escolar, uma vez que os organismos multilaterais atestam em seus estudos - mesmo que com critérios vagos - a emergência de novas políticas públicas curriculares voltadas à formação do empreendedor de si como uma proposta de formação integral, englobando o cognitivo e o socioemocional.

Pelo exposto anteriormente, notamos o quanto a OCDE, o IAS, entre outros ${ }^{5}$ têm ocupado um papel central no debate sobre as competências socioemocionais na educação brasileira.

Desse modo, as emoções são tomadas pelo imperativo mercadológico ${ }^{6}$, pela lógica do desempenho e da eficácia, produzindo um indivíduo produtivo, dócil e útil para o trabalho.

\footnotetext{
${ }^{4}$ Como se fosse possível fragmentar o processo de construção de conhecimentos em uma perspectiva racional e outra socioemocional.

${ }^{5}$ Fundação Lemann, Fundação Itaú Cultural, Unibanco, Burguer King, Natura, Boticário, para citar alguns.

6 A perspectiva do empreendedorismo, por influência da Teoria do Capital Humano tem influenciado as políticas públicas educacionais bem como os programas de formação docente. Essa presença na educação tornou-se marcante com a Conferência de Jontiem (1990) convocada pela Organização das Nações Unidas para a Educação, Ciência e Cultura (UNESCO), Programa das Nações Unidas para o Desenvolvimento (PNUD), Fundo das Nações Unidas para a Infância (UNICEF) e o BIRD. Essa ligação com os órgãos internacionais de financiamento é uma das características da racionalidade neoliberal. Dito de outro modo, a participação desses organismos na definição das políticas educacionais almeja a formação de mercados educativos por meio da perspectiva das competências racionais e socioemocionais.
} 
O imperativo agora não é buscar mais uma formação que leve em consideração apenas a competências cognitivas, mas também as socioemocionais, impondo uma corrida desenfreada pela inovação, pela criação e pelo empresário de si.

\begin{abstract}
Esse processo resulta no retorno ao Homo oeconomicus. O Homo oeconomicus não será mais entendido como um parceiro de troca a partir de suas necessidades, mas sim e sobretudo como um empresário de si, sendo ele próprio seu capital, seu produtor. Perceber o indivíduo como um sujeito governamentalizável, porque sua condição de Homo oeconomicus implica uma integral adesão do sujeito ao meio, ou seja, este será um sujeito que não questiona seu meio, que aceita a realidade e, portanto, procura explorar-se com o seu próprio capital (CIERVO; SILVA, 2019, p. 58).
\end{abstract}

De acordo com Cury (2018), a proposta de uma Base Nacional Comum Curricular, por exemplo, é um dispositivo intimamente alinhado à normatividade neoliberal. Assim, o conceito de educação de qualidade fica restrito à aquisição de competências (racionais e socioemocionais) e habilidades, formando, portanto, um indivíduo empreendedor de si.

Em outras palavras, na medida em que se explicam todas as mazelas educacionais pela ausência na escola de competências socioemocionais na formação dos estudantes, tais propostas reduzem a educação a um processo adaptativo, operacionalizador e meramente conformador.

Não é por acaso que os adeptos do empresariado educacional brasileiro sugerem que o trabalhador, como indivíduo ativo economicamente, incorpore a faceta do empresário de si mesmo, do self made man, uma vez que cabe a ele gerir sua produção laboral, desenvolvendo a máxima produtividade de forma eficiente e lucrativa. Essa maneira de estabelecer transações entre os indivíduos de consumo remonta à configuração de homo oeconomicus, um dispositivo de poder que exerce um domínio sobre o indivíduo.

Tais questões impõem ao indivíduo a responsabilidade pelo seu "Projeto de Vida", por seus fracassos e sucessos, ocultando o fato de que existem aspectos culturais, históricos e sociais que permeiam sua existência.

De acordo com Chauí (2016, p. 113), “a invenção da competência tem como alvo criar os incompetentes". Assim, podemos afirmar que, na medida que os problemas sociais são explicados pela falta de competências socioemocionais, as propostas formativas reduzem a educação a um processo adaptacionista comum a uma empresa 
qualquer, com atividades que preconizam o aprender a aprender em detrimento do aprender a pensar, a questionar. Essa perspectiva fica explícita, por exemplo, na lista de conteúdos elencados pela BNCC em que cada ano escolar deve priorizar no processo de ensino e de aprendizagem de seus estudantes. Não se pergunta por que determinados conteúdos devem ser ensinados.

Podemos pensar que o processo de construção do capitalismo emocional, no qual as emoções foram transformadas em microesferas públicas, transformou a emocionalidade, como discutido, em um nível instrumental, em um negócio significativo para o sujeito empresário de si. Supõe-se que, por meio do manejo e aprimoramento das emoções é possível tirar proveito delas em termos profissionais, sociais e pessoais, caracterizando, assim, certa instrumentalização de tais aspectos (CIERVO; SILVA, 2019, p. 398).

É nesse contexto que inserimos o debate sobre o conceito de governamentalidade de Foucault (2008). No texto "Segurança, território e população", o filósofo compreendeu que os sujeitos transformaram-se em agentes econômicos com a capacidade de valorizar e ampliar constantemente suas habilidades profissionais a fim de tornarem-se competitivos no mercado neoliberal.

Tal conceito oferece importantes elementos para pensarmos o novo papel biopolítico que a escola pós-disciplinar assume na contemporaneidade.

As políticas públicas atuais tomam o corpo dos estudantes como instrumentos para intervenções operacionalizadas dentro de novas configurações governamentais. $\mathrm{Na}$ leitura foucaultiana, a escola é um dos dispositivos que produz práticas de governamento.

Moraes (2008) pontuou que as pedagogias executadas no interior das escolas (processo de ensino e de aprendizagem, currículos, exames, metodologias e didáticas permeadas pelo desenvolvimento de competências socioemocionais) constituem práticas de governamento de si.

De acordo com o pensamento foucaultiano (2008), a governamentalidade constitui-se por um conjunto de mecanismos e ferramentas de dispositivos de governo, exercendo um gerenciamento da população.

Diante do assinalado, insere-se o debate sobre competências socioemocionais como um dispositivo de governamentalidade capaz de conduzir determinada conduta.

\section{ESCOLA, CURRÍCULO E GOVERNAMENTALIDADE}


O conceito de governamentalidade é de fundamental importância para se pensar a educação e as práticas educacionais que nela se desenvolvem.

Este item pretende desenvolver uma reflexão sobre o tema da governamentalidade articulado às estratégias políticas do Estado em constituir a "gestão da vida" "através de dispositivos de controle como as competências socioemocionais, objeto da presente reflexão.

Podemos afirmar que o termo governamentalidade surgiu em Foucault no texto "Segurança, território e População" - curso ministrado pelo filósofo no Collège de France, de janeiro a abril de 1978 -, como tentativa de caracterizar as diferentes formas pelas quais cada um governa a si mesmo e aos outros.

\begin{abstract}
Por esta palavra governamentalidade entendo o conjunto constituído pelas instituições, os procedimentos, análises e reflexões, os cálculos e táticas que permitem exercer essa forma bem específica, embora muito complexa, de poder que tem por alvo principal a população [...] (FOUCAULT, 2008, p. 143).
\end{abstract}

Relacionado ao campo educativo, esse conceito é de suma importância, uma vez que a escola, ao invés de ser vista apenas como um espaço no qual se ensinam conteúdos específicos, passa a ser entendida como uma instituição encarregada de produzir novas subjetividades alinhadas ao empreendedorismo mundial.

\begin{abstract}
Nesse contexto, educar para o empreendedorismo não se constitui em nenhuma novidade, como querem fazer crer seus apologetas: pelo contrário, pretende revivificar, embora de forma empobrecida, as velhas formas do pensamento liberal clássico aos tempos atuais e protagonizar a formação de um indivíduo aguerrido ao desejo de realização de sucesso pessoal (COAN, 2011, p. 458).
\end{abstract}

Desde os primórdios, há um consenso quanto à importância da escola na formação dos sujeitos.

Na escola e nos mais diversos discursos políticos, também há o consenso de que os estudantes devem ser preparados para o competitivo mercado de trabalho. Aqui, as organizações internacionais e nacionais sugerem modelos formativos pautados por competências socioemocionais enquanto estratégias (de controle) na fabricação de

\footnotetext{
${ }^{7}$ Foucault (2008) utiliza a ideia de "gestão da população" no contexto da biopolítica. Desse modo, ao nos referirmos à "gestão da vida" estamos nos referindo às estratégias de poder que fazem parte do domínio dos aparelhos do Estado bem como das instituições como escolas, empresas, dentre outras.
} 
subjetividades. Tais modelos orientam as práticas educacionais no sentido de desenvolver capacidades para que o indivíduo esteja aberto ao mundo emocional, seja capaz de ligar emoção e pensamento, desenvolver a capacidade de regular as emoções, que tenha capacidade de moldurar as emoções, entre outras.

\begin{abstract}
Dessa forma, a escola foi inventada para disciplinar e exercer governamento sobre os sujeitos modernos, dispensando o uso da violência, valendo-se de métodos sutis de persuasão que agem de forma indiretas sobre suas escolhas, seus desejos e sua conduta, deixando-os "livres para escolher", mesmo que constantemente envolvidos por normas que os aprisionam a própria consciência (OLIVEIRA; VALEIRÃO, 2013, p. 564).
\end{abstract}

Desse ponto de vista, a escola atua como um dispositivo ${ }^{8}$ com a função de dizer o que pode ser feito ou pensado. Assim, o aprender a aprender constantemente tem prevalência sobre o aprender a pensar, uma vez que as políticas neoliberais ${ }^{9}$ ditam as normas que devem ser seguidas por todos. Assim, faz-se necessário incluir na formação dos estudantes pedagogias ajustadas aos padrões eleitos pelo mercado global competitivo, a exemplo da pedagogia das competências socioemocionais.

Portanto, esse novo dispositivo ${ }^{10}$ presente na sociedade contemporânea faz com que a escola se prontifique a cada vez mais formar sujeitos que sejam empresários de si, ou seja, sujeitos que sejam aptos a conduzir a si mesmos permeados pelo imperativo do aprender a aprender empreendendo-se.

Um exemplo do que citamos acima pode ser subtraído do texto "Dez novas competências para ensinar”, de Perrenoud (1999), no qual o autor caracteriza um indivíduo competente como: ter boa formação empírica, trabalhar em equipe, fazer uso de novas tecnologias, aprender a aprender incessantemente, aprender a conviver juntos, dentre outros.

\footnotetext{
${ }^{8}$ No debate sobre governamentalidade, Foucault (2008) investiu em múltiplas facetas do dispositivo. Podemos citar alguns: dispositivo de poder, dispositivo de segurança, dispositivos de saber, dispositivos psiquiátricos, dispositivos de soberania, dispositivos disciplinares, dispositivo político de polícia e dispositivos de sexualidade.

9 Foucault (2008) estava preocupado em como as subjetividades são moldadas no contexto do neoliberalismo.

${ }^{10}$ É no texto História da Sexualidade (vol. 1 - A vontade de saber) que Foucault (1980) desenvolve as definições de dispositivo, apesar de já ter apresentado tal conceito em Vigiar e Punir. Foucault (1980, p. 244) conceituou dispositivo como: [...] um conjunto decididamente heterogêneo que engloba discursos, instituições, organizações arquitetônicas, decisões regulamentares, leis, medidas administrativas, enunciados científicos, proposições filosóficas, morais e filantrópicas. [o dispositivo pode ser entendido também] como um tipo de formação que, em determinado momento histórico teve como função principal responder a uma urgência histórica. $\mathrm{O}$ dispositivo tem, portanto, uma função estratégica dominante.
} 
Diante do assinalado, a lógica do empresário de si constitui-se como um modelo ideal do autogoverno formativo. Trata-se, portanto, de um assujeitamento dos corpos às técnicas de governamentalização neoliberal. Em outras palavras, com a nova governamentalidade, fica explícita cada vez mais a noção de administração de pessoas e coisas.

O que Foucault (2008) denuncia é que o neoliberalismo produz a necessidade da formação de um capital humano desde a mais tenra idade, no qual o sujeito tem validade enquanto seu capital humano é útil aos interesses empresariais.

Assim, quanto mais especializado for seu capital humano, maior a possibilidade de crescimento da empresa, do empresariamento de si.

\begin{abstract}
Esta nova tecnologia de governamento presente na sociedade atual faz com que a escola, enquanto máquina de governamentalidade esteja cada vez mais preocupada em formar sujeitos que saibam conduzir a si mesmos ou, como já foi dito, sujeitos que sejam empresários de si. Em suma, a escola atua como uma maquinaria encarregada de preparar competências que orientem os futuros sujeitos clientes a atuarem num mundo marcado pelo mercado e pela competição (OLIVEIRA, VALEIRÃO, 2013, p. 575).
\end{abstract}

Esse debate sugere que o permanente investimento do empresário de si pode levá-lo a adquirir cada vez mais competências aumentando as suas chances de empregabilidade, uma vez que ele estará mais resiliente de posse de competências socioemocionais.

Dito de outra forma, podemos interpretar as considerações acima como uma estratégia de marketing pessoal, de gestão da vida de acordo com os modelos eleitos pelo capital neoliberal.

A Associação Nacional de Pós-Graduação e Pesquisa em Educação (ANPED, 2014) demonstrou sua posição contrária ao modo como as competências socioemocionais estão sendo propagadas pelas instituições privadas. De acordo com a referida Associação, formulam-se os seguintes questionamentos: o que poderá resultar da avaliação de habilidades socioemocionais: premiação daqueles alunos que se conformarem aos valores estabelecidos? Segregação para aqueles que não apresentam as habilidades tomadas como as necessárias?

Ainda no contexto de evidenciar os limites de uma pedagogia pautada por competências socioemocionais, o Conselho Regional de Psicologia de São Paulo (2015) publicou uma nota de repúdio sobre a avaliação em larga escala das competências 
socioemocionais de crianças e adolescentes. O órgão fomentou que as avaliações socioemocionais são instrumentos com características segmentadoras e discriminativas.

Depreende-se que a orientação agora não é mais direcionada ao emprego, mas à empregabilidade do sujeito. Resumindo, se o indivíduo não consegue uma vaga no tão almejado emprego é porque ele não adquiriu competências suficientes que garantissem sua empregabilidade. Ao que parece, "o ambiente escolar continua sendo tratado segundo um viés utilitarista, como uma peça a ser movimentada pelos jogadores, garantindo-lhes o sucesso da disputa (WEINHELMER, 2019, p. 119).

O debate sobre competências socioemocionais captura a escola e exige dela a produção do empresário de si. Tudo necessita ser otimizado: o tempo, a formação e a aquisição de competências.

\footnotetext{
Aqui a escola não é vista como um espaço que disponibiliza tempo, mas que o ocupa de determinada maneira, sobrepesando os alunos que têm outras ocupações em vista, podendo ser - na perspectiva discente - mais interessantes e relevantes do que a própria preparação para o futuro. Se todas as horas forem empregadas com vista à empregabilidade, outras atividades deixarão de ser feitas por falta de tempo. Como ler um livro se não há tardes liberadas dos conteúdos escolares? Como instaurar um pensamento demorado sobre si, sobre o mundo, sobre aquilo que nos rodeia, nos afeta, nos desassossega se não há tempo de sobra? (WEINHEIMER, 2019, p. 122).
}

A partir de uma leitura foucaultiana, podemos inferir que o corpo biopolítico é atingido pelo poder de governo, seja para regulá-lo, para bani-lo ou para torná-lo um corpo dócil, ou seja, um indivíduo economicamente produtivo e politicamente submisso.

A exemplo do debate sobre competências socioemocionais, refletir sobre o momento histórico atual abre uma variedade de opções para entender o modo como o indivíduo vem se subjetivando, bem como compreender os dispositivos discursivos que versam sobre essa subjetivação.

\section{COMO RESISTIR: ESCOLA COMO ESPAÇO DE CONTRACONDUTA}

Pensar a educação sob uma perspectiva foucaultiana implica adentrar no problema da condução, da governamentalidade, dos dispositivos que a constituem. 
Embora pouco tematizou sobre a educação, Foucault (1984) permitiu pensar em articulações entre Educação e resistência.

O que fica nítido em seu pensamento é a interrogação sobre os modelos de ciência que a modernidade possibilitou surgir e, com ela, o modo como a Pedagogia se instrumentalizou de dispositivos para constituir as subjetividades em que "[...] os modos de subjetivação são, precisamente, as práticas de constituição do sujeito" (CASTRO, 2009, p. 408).

Em contextos neoliberais, esses processos ganharam notoriedade com as chamadas Pedagogias das competências socioemocionais engendrando aquilo que Foucault (2008) denominou de governamentalidade.

Desse modo, o autor deixou claro que estamos diante de um dispositivo produtor de indivíduos economicamente produtivos e politicamente submissos.

[...] a escola funciona como operador de pedagogização, pois reúne a capacidade de habilitar com recursos educacionais básicos a criança e o jovem, com a capacidade de fornecer os mecanismos e instrumentos pedagógicos que asseguram obediência, responsabilidade, prontidão, docilidade, adaptabilidade (ARAÚJO, 2002, p. 78).

Araújo (2002) destacou o quanto as instituições educacionais são subordinadas às organizações multilaterais - a exemplo do IAS e a OCDE - no sentido de modernizar suas finalidades de acordo com as transformações do mundo do trabalho.

Se retomarmos a dupla articulação assujeitamento/subjetivação podemos inferir que ao sermos subjetivados como cidadãos, no contexto da governamentalidade democrática brasileira contemporânea somos assujeitados, mas isso também nos abre o panorama de atuarmos sobre nós mesmos (GALLO, 2017, p. 89-90).

Diante da amplitude que caracteriza a temática, nota-se que problematizar a contemporaneidade é compreendê-la em seus modos de subjetivação que caracterizam os sujeitos em suas múltiplas relações.

Em Foucault (1984), problematizar o hoje é entendê-lo como acontecimento compreendido como imprevisibilidades que abrem possibilidades diante da realidade. Dito de outro modo, problematizar o hoje é desenvolver uma interrogação crítica do sujeito. Pode-se dizer, com Foucault (1984, p. 14), que problematizar a atualidade é fazer uma ontologia de nós mesmos, pois "é esta a tarefa de uma história do pensamento 
por oposição à história dos comportamentos ou das representações: definir as condições nas quais o ser humano problematiza o que ele é, e o mundo no qual ele vive".

No debate sobre a Pedagogia das competências socioemocionais, sugere-se ao sujeito a modificação de sua relação consigo mesmo, a problematização de sua realidade, não aceitando docilmente os modelos que são impostos à Educação sem uma reflexão e problematização contínuas.

Refletir sobre o presente problematizando-o é a possibilidade que Foucault (1984) apresentou ao sujeito de pensar, agir e projetar uma vida ausente de determinismos e padrões de ser pré-concebidas, uma vez que o discurso do "sujeito que problematiza sua atualidade deve converter-se em prática de vida, em modos de agir que estilizem a vida e ao mesmo tempo seja reflexo de uma íntima relação consigo ocasionada pelo cuidado e conhecimento de si” (OLIVEIRA, 2011, p. 137).

Como citado anteriormente, a problematização crítica do presente abre possibilidades para o sujeito pensar a si $\operatorname{mesmo}^{11}$ e os possíveis dispositivos os quais está subordinado.

Nesse debate, chama-se a atenção para a problematização do presente diante das relações permeadas por poderes e saberes oriundos de organizações que privilegiam a produção de corpos dóceis, de empresários de si.

Em Foucault (2008), a Filosofia oportuniza ao sujeito a possibilidade de problematizar criticamente a realidade.

Na Microfísica do Poder, Foucault (2005, p. 305) pontuou que "é filosofia o deslocamento e a transformação dos parâmetros de pensamento, a modificação dos valores recebidos e todo o trabalho que se faz para pensar de outra maneira, para fazer outra coisa, para tornar-se diferente do que se é ".

Nesse momento do debate, podemos acrescentar: qual a relação entre atitude crítica e os modos de governamentalização?

Segundo Gallo (2017, p. 34), "a crítica como atitude é a arte de não ser governado de tal maneira". Dito de outro modo, a atitude crítica na perspectiva

\footnotetext{
${ }^{11}$ Ao processo de transformação que o sujeito realiza sobre si mesmo e sobre os condicionamentos os quais é governado Foucault dá o nome de estética da existência. De acordo com Miskolci e Simões (2008, p. 235) "a estética da existência implica transformar-se e constituir formas de resistência ao enquadramento em formas de vida socialmente prescritas".
} 
foucaultiana pode ser entendida como uma forma de contraconduta, como uma forma de luta contra os dispositivos que visam governar as vidas.

\begin{abstract}
Se a governamentalização é realmente o movimento pelo qual se tratava, na própria realidade de uma prática social, de submeter os indivíduos por mecanismos de poder que se reclamam de uma verdade, bem, direi que a crítica é o movimento pelo qual o sujeito se outorga o direito de interrogar a verdade sobre os seus feitos de poder e o poder sobre os seus discursos de verdade; a crítica seria assim a arte da insubmissão voluntária, a da indocilidade refletida. A crítica teria essencialmente por função a "dessubmissão" no jogo daquilo que se poderia chamar, em suma, a política da verdade (GALLO, 2017, p. 36).
\end{abstract}

$\mathrm{Na}$ perspectiva que aqui se adota para estudar o tema das competências socioemocionais, a crítica como atitude se traduz como uma proposta pela qual os indivíduos podem resistir às técnicas de controle de si que tentam governá-los.

Assim, relacionando a problematização das competências socioemocionais às contribuições teóricas foucaultianas, pensa-se ser possível resistir às técnicas de governamento, recusando as formas de conduta de si e dos outros, principalmente nos dias atuais nos quais as tecnologias de si aliadas ao capitalismo neoliberal gerenciam as subjetividades, negando a criticidade e a contraconduta.

\title{
5 ALGUMAS CONSIDERAÇÕES
}

Trouxe-se à presente reflexão a crítica sobre como a sociedade investida de dispositivos de controle faz dos sujeitos instrumentos destes.

Neste artigo, optou-se pela discussão sobre a governamentalidade, problematizando o presente e a relação que o sujeito estabelece com a perspectiva do empresário de si.

O conceito de governamentalidade serviu de suporte para entendermos como as organizações neoliberais endossam a produção de subjetividades assujeitadas, a exemplo da pedagogia das competências socioemocionais. Tal conceito promove a criação de novas subjetividades impostas por poderes presentes no tecido social.

Com efeito, todo o projeto educacional moderno e contemporâneo diz respeito às formas de governo ou da governamentalidade, ora disciplinar, no passado, ora biopolítico e neoliberal no presente. Dessa forma, resistir ou criar possibilidades outras na educação implicará aprender a (des) governar, 
isto é, a criar espaços de (des) governo em um mundo cada vez mais controlado e governado (CÉSAR, 2010, p. 239).

Problematizar o presente criticamente em busca de uma reformulação contínua das subjetividades é a possibilidade que Foucault (2008) oferece ao sujeito para resistir às formas de assujeitamento.

É uma das possibilidades de o sujeito agir além dos determinismos neoliberais libertando-se dos modos de viver desse jeito. Como citado anteriormente, a crítica atrelada à problematização promove no sujeito foucaultiano a possibilidade de pensar a si à medida que conhece a si e constrói a si.

Finalizando, resistir às formas de governamentalização da vida é insistir na produção de outras subjetividades que não aquelas emanadas da pedagogia das competências socioemocionais: adestramento, competitividade, adaptação, controle, empreendedor de si.

Rejeitar esse sujeito empresário de si - o qual fomos transformados para sermos governados - é apostar na vida para além das formas de governos atuais, possibilitando outras formas subjetivas. Os sistemas educativos "se nos conformam a esta subjetividade podem também abrir outras formas de nos relacionarmos conosco, produzindo formas outras de vida" (GALLO, 2017, p. 92).

\section{REFERÊNCIAS}

ASSOCIAÇÃO NACIONAL DE PÓS-GRADUAÇÃO EM PESQUISA E EDUCAÇÃO. Carta aberta sobre avaliação em larga escala de habilidades não-cognitivas de crianças e jovens. Rio de Janeiro, 7 nov. 2014. Disponível em: http://www.anped.org.br/news/carta-aberta-sobre-avaliacao-em-larga-escala-dehabilidades-nao-cognitivas-de-criancas-e-jovens. Acesso em: 16 mar. 2020.

ARAÚJO, Inês. L. de Da "Pedagogização" à Educação: Acerca de Algumas Contribuições de Foucault e Habermas para a Filosofia da Educação. Revista Diálogo Educacional, v. 3, n. 7, p. 75-88, set/dez 2002.

BRASIL. Base Nacional Comum Curricular (BNCC). Educação é a Base. Brasília, MEC/CONSED/UNDIME, 2017. Disponível em: http://basenacionalcomum.mec.gov.br/images/BNCC_publicacao.pdf $>$. Acesso em: 02 fev. 2020.

BRASIL. Lei $\mathbf{n}^{\mathbf{0}}$ 13.415, de 13 de fevereiro de 2017. Institui a Política de Fomento à Implementação de Escolas de Ensino Médio em Tempo Integral. 2017. Disponível em: 
< http://www.planalto.gov.br/ccivil_03/_ato2015-2018/2017/lei/L13415.htm>. Acesso em: 24 fev. 2020.

BRASIL. Lei $\mathbf{n}^{\circ} \mathbf{1 3 . 0 0 5}$, de 25 de junho de 2014. Aprova o Plano Nacional de Educação - PNE e dá outras providências. Diário Oficial da União, Brasília, DF., 26 jun 2014. Disponível em: http://pne.mec.gov.br/18-planos-subnacionais-de-educacao/543plano-nacional-de-educacao-lei-n-13-005-2014. Acesso em: 23 fev. 2020.

BRASIL. Lei de Diretrizes e Bases da Educação Nacional. Lei n ${ }^{\circ}$ 9394, de 20 de dezembro de $1996 . \quad$ Disponível em: https://www2.senado.leg.br/bdsf/bitstream/handle/id/529732/lei_de_diretrizes_e_bases_ 1ed.pdf. Acesso em: 15 fev. 2020.

CARVALHO, Rodrigo; SILVA, Roberto Rafael. Currículos socioemocionais, habilidades do século XXI e o investimento econômico na educação: as novas políticas curriculares em exame. Educar em Revista, Curitiba, ${ }^{\circ}$ 63, p. 173-190, jan./mar. 2017.

CASTRO, Eduardo; XAVIER, Ingrid. Vocabulário de Foucault: um percurso pelos seus temas, conceitos e autores. Tradução Ingrid Muller Xavier. Belo Horizonte: Autêntica, 2009.

CESAR, Maria Rita de A. (Des) governos: biopolítica, governamentalidade e educação contemporânea. ETD - Educação Temática Digital, Campinas, v. 12 , n. 1, p. 224241, jul./dez, 2010.

CHAUÍ, Marilena. A ideologia da competência. In: ROCHA, André (org.). Escritos de Marilena Chauí. São Paulo: Ed. Fundação Perseu Abramo, 2016, p. 113-121.

CIERVO, Tássia J. R; SILVA, Roberto Dias. A centralidade das competências socioemocionais nas políticas curriculares contemporâneas no Brasil. Revista ECurriculum, São Paulo, v.17, n. 2, p. 382-401 abr./jun. 2019.

COAN, Marival. Educação para o empreendedorismo: implicações epistemológicas, políticas e práticas. 540 f. Tese (Doutorado em Educação) - Universidade Federal de Santa Catarina, Florianópolis, 2011.

CONSELHO REGIONAL DE PSICOLOGIA DA 6a REGIÃO. Nota de Repúdio do Conselho Regional de Psicologia de São Paulo sobre a Avaliação em Larga Escala das Habilidades Socioemocionais de Crianças e Jovens. CRP-06 Associação Brasileira de Psicologia Escolar e Educacional - ABRAPEE Grupo Interinstitucional Queixa Escolar - GIQE, 2015.

CURY, Carlos R. Base Nacional Comum Curricular: dilemas e perspectivas. São Paulo: Cortez, 2018.

FOCAULT, Michel. Segurança, território e população. São Paulo: Martins Fontes, 2008. 
História da sexualidade: A vontade de saber. Tradução de Maria Tereza da Costa Albuquerque. Rio de Janeiro: Edições Graal, 1980, v.1.

História da sexualidade: o uso dos prazeres. Tradução de Maria Tereza da Costa Albuquerque. Rio de Janeiro: Edições Graal, 1984, v.2.

Graal, 2005.

Microfísica do poder. 21 ed. Tradução de Roberto Machado. Rio de Janeiro:

Vigiar e Punir: nascimento da prisão. Tradução de Raquel Ramalhete. Petrópolis: Vozes, 1984.

GADELHA, Sylvio. Biopolítica, Governamentalidade e Educação: introdução e conexões a partir de Michel Foucault. Belo Horizonte: Autêntica, 2009.

GALLO, Sílvio. Biopolítica e subjetividade: resistência? Educar em revista, Curitiba, n. 66, p. 77-99, out./dez. 2017.

HECKMAN, James. J. Giving kids a fair chance: a strategy that works [recurso eletrônico]. Boston Review Books, 2013.

INSTITUTO AYRTON SENNA (IAS) - UNESCO. Competências socioemocionais: material para discussão (2015). Disponível em: http://www.educacaosec21.org.br. Acesso em 16 fev. 2020.

Sobre o desenvolvimento de competências nas escolas. Edulab21, INSPER Núcleo de Pesquisa em Ciências para a educação, 2016. Disponível em: https://institutoayrtonsenna.org.br > edulab21Livro_TomandoNota_Final. Acesso em: 10 jan. 2020.

Educação para o século 21, 2013. Disponível em:https://www.institutoayrtonsenna.org.br/pt-br/conteudos/educacao-e-inovacao-noseculo-XXI.html. Acesso em: 14 fev. 2020.

Fórum Internacional de Políticas Públicas "Educar para as competências do século 21”. São Paulo, 24 e 25 março 2014.

; MEC; OCDE. Seminário Educação para o século XXI, 2011. Disponível em: http://www.educacaosec21.org.br/foruminternacional2014/wpcontent/uploads/2014/01/ comunicado-de-imprensa-f\%C3\%B3rum.pdf. Acesso em: 20 fev. 2020.

; UNESCO. Competências socioemocionais: material de discussão. [S. 1.]: IAS, UNESCO, 2013. Disponível em: http://educacaosec21.org.br/wpcontent/uploads/2013/07/COMPET\%C3\%8ANCIASSOCIOEMOCIONAIS_MATERI AL-DE-DISCUSS\%C3\%830_IAS_v2.pdf. Acesso em: 9 fev. 2020. 
MISKOLCI, Richard; SIMÕES, Júlio Assis (Orgs.). Dossiê: sexualidades disparatadas. Cadernos Pagu, Campinas, SP, n 28, p. 9-18, jan./jun. 2008.

MORAES, Antônio Luís. Disciplina e controle na escola: do aluno dócil ao aluno flexível. Canoas, RS: Contraponto, 2008.

OLIVEIRA, Avelino; VALEIRÃO, Kelin. Governamentalidade e práxis educacional na contemporaneidade. Educação e Filosofia. Uberlândia, v. 27, n. 54, p. 559-578, jul./dez. 2013.

OLIVEIRA, Gilberto. Cuidado de si e hermenêutica do sujeito em Michel Foucault. Dissertação (Mestrado) - Universidade Federal do Rio Grande do Norte. Programa de Pós-graduação em Filosofia, Natal, RN, 2011, 160 f.

ORGANIZAÇÃO PARA A COOPERAÇÃO E DESENVOLVIMENTO ECONÔMICO (OCDE). Pisa em foco, $n^{\circ}$ 5, jun. 2015.

PERRENOUD, Phillipe. Dez novas competências e habilidades para ensinar. Porto alegre: Artmed, 1999.

PRIMI, Ricardo; SANTOS, Daniel. Desenvolvimento socioemocional e aprendizado escolar: uma proposta de mensuração para apoiar políticas públicas. São Paulo: OCDE, Instituto Ayrton Senna, Governo do Rio de Janeiro, 2014.

SECRETARIA DE EDUCAÇÃO DO ESTADO DO RIO DE JANEIRO; INSTITUTO AYRTON SENNA. Diretrizes para a Política de Educação Integral: Solução Educacional para o Ensino Médio. Caderno 2: Modelo Pedagógico: princípios, metodologias integradoras e avaliação da aprendizagem. Rio de Janeiro: SEEDUC/RJ; IAS, 2014.

UNESCO. $O$ desenvolvimento das habilidades socioemocionais como caminho para a aprendizagem e o sucesso escolar de alunos da educação básica. São Paulo: 2014.

Declaração Mundial sobre Educação para Todos: satisfação das necessidades básicas de aprendizagem. UNESCO: Jomtien, 1990.

VEIGA-NETO, Alfredo. Foucault e a educação. 3. ed. Belo Horizonte: Autêntica, 2011.

WEINHEIMER, Gicele. Rastros da governamentalidade e da contraconduta neoliberais na escola pública contemporânea. Dissertação (Mestrado) -- Universidade Federal do Rio Grande do Sul, Faculdade de Educação, Programa de Pós-Graduação em Educação, Porto Alegre, RS, 2019, 